\title{
The Human Capital Valuation in IC Paradigm: An Empirical Proposal
}

\author{
Domenico Celenza, Fabrizio Rossi \\ University of Cassino and Southern Lazio, Cassino, Italy
}

\begin{abstract}
Intellectual Capital (IC) is an important source of value for companies and in recent years has been the focus of attention for scholars. In a knowledge-based economic scenario, the role of human resources has been reallocated over time in the theory of the firm to a higher degree than in the past. The worker's labor and management have been transformed as a result of the growing attention to the intangible assets held by each business system. In knowledge economy, manufacturing industries are investing more and more in the processes of scientific and technological research in order to introduce new knowledge in production systems and ensure its survival by creating business value. The competitive firm invests in new productive ideas through scientific and technological research, the human factor and services. The knowledge worker, at every organizational level, has the knowledge that allows the organization to be competitive and deal with the complexity of the environment by creating intellectual added value. The traditional factors of "old economy” based on physical assets has been replaced, or at least reinforced with the belief that the "new economy" takes it steps mainly through IC. The aim of this paper is to examine the methods of evaluation of human capital and to provide an empirical methodology proposed by using an intersection logic concerning the increase in value of the three components of intellectual capital. In particular, the proposed methodology consists in the construction of an adjusted multiplier based on a simplified version of VAIC $^{\mathrm{TM}}$ capable of expressing a direct relationship with the Return on Equity (ROE) from the perspective of creating value for shareholders based on the dynamics of the company's performance compared with that of industry.
\end{abstract}

Keywords: human capital, intellectual capital, evaluation method, Value Added Intellectual Coefficient (VAIC ${ }^{\mathrm{TM}}$ ), knowledge based firms

\section{Introduction}

Intellectual Capital (IC) is an important source of value for companies and in recent years has been the focus of attention for scholars. The relationship between physical assets and human assets, seen as a complementary relationship, is also emphasized in the work of Grossman and Hart (1986), Hart (1995) and Hart and Moore (1990, 1994).

In a knowledge-based economic scenario, the role of human resources has been reallocated over time in

Domenico Celenza, Ph.D. in Business Economics, Researcher in Business Economics, Department of Economics and Law, University of Cassino and Southern Lazio.

Fabrizio Rossi, Ph.D. in Management Engineering, Adjunct Professor of Economics and Business Organisation, Department of Electrical and Information Engineering, University of Cassino and Southern Lazio.

Correspondence concerning this article should be addressed to Fabrizio Rossi, University of Cassino and Southern Lazio, Via G. Di Biasio 43, Cassino, Italy. E-mail: f.rossi@unicas.it. 
the theory of the firm to a higher degree than in the past. The worker's labor and management have been transformed as a result of the growing attention to the intangible assets held by each business system. In knowledge economy, manufacturing industries are investing more and more in the processes of scientific and technological research in order to introduce new knowledge in production systems and ensure its survival by creating business value. Service companies, however, are witnessing a significant increase in competitiveness and productivity in the service sector which benefits from the simplification of work, the increase of the importance of IC in order to achieve a competitive differential in the market (Trequattrini, 2008), and from the light structure of the company which rents the assets necessary to perform the task.

The competitive firm invests in new productive ideas through scientific and technological research, the human factor and services. The knowledge worker, at every organizational level, has the knowledge that allows the organization to be competitive and deal with the complexity of the environment, creating intellectual added value (Prandstraller, 2009; Zanda, 2009). The knowledge worker, in this view, is similar to the homo empaticus. Rifkin (2010), as the sharing of knowledge requires an empathic process that moves from sociality and from the sense of collaboration, both innate in humans. At the same time, the knowledge worker is identified with the homo faber (Rifkin, 2001), that is, the man who produces by sharing his own knowledge for collective purposes. According to Drucker (2003), the success and survival of a company depends on the performance of knowledge workers as the company is at the service of workers who have a distinctive means of production: knowledge. For these reasons, knowledge workers are “...social actors who possess the means of intellectual production regardless of whether they are employees, professionals, unemployed or underemployed, regardless of whether they are engineers, technicians, designers, artists, or rather employed in routine jobs” (Grazzini, 2008). In this perspective, knowledge workers, whether they are skilled workers or managers, are knowledge workers, each possessing specific skills. Basically it emphasizes the importance of the particular relationship and complementarity, since the company is a sum of assets (Moore, 1992). The traditional factors of the "old economy", based on physical assets, have been replaced, or at least reinforced with the belief that the "new economy" takes its steps mainly through IC.

The aim of this paper is to examine the methods of evaluation of human capital and to provide an empirical methodology proposed by using an intersection logic concerning the increase in value of the three components of intellectual capital.

In particular, the proposed methodology consists in the construction of an adjusted multiplier based on a simplified version of VAIC $^{\mathrm{TM}}$ capable of expressing a direct relationship with the Return on Equity (ROE) from the perspective of creating value for shareholders based on the dynamics of the company's performance compared with that of industry.

\section{Literature Review}

Several empirical studies demonstrate the impact of intangible assets both on the company's financial performance and on stock returns. Aboody and Lev (2000) showed that the impact that generates IC on current and future operating earnings is very strong. With reference to the chemical industry, for example, they show that the increase in R\&D investments doubled operating profits.

Bornemann, Knapp, Sixl, and Schneider (1999) found that firms that manage their IC more effectively were able to secure a very strong competitive advantage over other companies and perform better than them.

There is no single definition of IC. Stewart (1997) for example, defined IC as the "packaging of useful 
knowledge”. Petty and Guthrie (2000) instead give IC a much more incisive meaning, considering it instrumental both in determining the value of the company and improving the economic performance of a nation.

In the literature, there is also a widely accepted idea of the existence of a strong relationship between IC and the market value of firms. For example, Lev and Zarowin (1999), Lev (2001), Lev and Radhakrishnan (2003) have focused on the gap between the market value and book value of companies while trying to investigate the invisible values that do not appear in financial statements. More generally, there have been hypotheses about the weight that IC can have on the value of the company and on the need to consider not only the financial variables but also include the value of IC. Edvinsson and Malone (1997), indeed, give the value of IC the difference between the market value and book value of the company.

Pulic (2000) offered an additional measure of the value of IC through the Value Added Intellectual Coefficient (VAIC ${ }^{\mathrm{TM}}$ ) which includes both physical capital and human and structural capital.

Firer and Williams (2003) tested the VAIC ${ }^{\mathrm{TM}}$ but could not find a strong relationship with the company's profitability.

On the contrary, Chen, Cheng, and Hwang (2005) found that IC has a very strong impact on the market value and performance of firms. In particular, investments in R\&D can provide additional information on structural capital and generate a positive effect on firm value and profitability.

Kamath (2008) however does not see any relation between IC and the traditional performance measures such as profitability and market value. Even Ghosh and Mondal (2009), after investigating 80 companies operating in the pharmaceutical and information sector and testing the relationship between IC and company performance, found that market value and productivity are not significantly related to IC, however, they pointed out that IC is a good predictor of productivity.

A different approach to the traditional evaluation methods is proposed by Cricelli and Grimaldi (2009). The two authors, through the Hyerarchical Assessment Index (HAI) model, point to the identification of new drivers that can have a significant impact on the various components of IC.

Venugopal and Subha (2012) examined 41 firms producing software in India during the period 2000-2010 and found that although the efficiency of capital employed and the efficiency of structural capital are both significantly and positively related to financial performance, there is no direct relationship between the VAIC as an indicator for measuring IC, and financial performance. The authors emphasize, however, that "the model which studied the relationship between components of VAIC ${ }^{\text {TM }}$ and financial performance explained the firm's value better” (p. 130).

\section{Evaluation Methods}

In general, the methods of IC evaluation can be divided into direct and indirect. The first is based on the measurement of the value of intangible assets and indirect methods aim at the measurement of IC through rates of return and the market value of the company. However, like in all the estimates of the value of the company, the choice of model measuring IC varies according to the reference context and analysis perspectives and more precisely according to the purpose, situation, and audience of users (Sveiby, 2001).

In theory, the estimation methods of IC are divided into two categories: analytical and synthetic.

The first allows the determination of the economic value of intellectual capital as the sum of its components: human capital, relational capital, and structural capital. In formula: 
where:

$$
\mathrm{IC}=\mathrm{HC}+\mathrm{RC}+\mathrm{SC}
$$

IC represents the economic value of intellectual capital; HC, RC, and SC are, respectively, the economic value of human capital, relational capital, and structural capital.

The synthetic method, however, relates the IC to the concept of goodwill, which is determined as the difference between the value of the economic capital of the holding company of intellectual capital being estimated and its adjusted net assets. In formulas:

where:

$$
\mathrm{IC}=\mathrm{W}-\mathrm{K}^{\prime}
$$

$\mathrm{W}$ is the value of the economic capital of the holder of intellectual capital;

$\mathrm{K}^{\prime}$ is the adjusted net assets of the company.

In what follows, we will analyze the main methods of estimating intellectual capital according to the analytical and synthetic methods.

Human capital is identified with the people who are part of the organization, or with their skills, experience, motivation, knowledge, intellectual skills, which are used in the management of the company.

\section{Human Capital Evaluation Methods}

Teaching and practice have provided a classification of methods for estimating human capital, dividing them into qualitative methods and quantitative methods.

The first are those that do not care about identifying a monetary value for human capital but identify the variables and relationships that can determine their increase in value.

The latter, however, tend to identify the economic value of human capital and can be classified into methods based on costs, methods based on economic profit and empirical methods.

The former, which are inspired by Human Resource Accounting (HRA), can be classified as follows:

- Methods based on historical cost;

- Method based on opportunity cost;

- Method based on replacement cost;

- Economic income methods.

In the original formulation, the method based on historical cost is based on the identification of all the costs which are necessary to purchase, select and train human resources and the subsequent capitalization at a rate equal to inflation for the period of evaluation.

The subsequent formulations of this model have led to include in total capitalized costs also fringe benefits and all the costs that the company incurs to acquire and retain staff.

It was observed that the wording of the historical cost method is a moment when the conceptualization of labor as an operating cost is surpassed in order to consider it instead as a use of funds assets (Zanda \& Lacchini, 1994).

The same authors, however, identify a series of critical issues in the application of this method, since the appreciation of the historical cost does not provide information on the efficiency and effectiveness of the style of direction and, therefore, does not allow to have cognizance of any inefficiencies due to an inefficient management style and they emphasize the difficulty over time of finding and rating and reviewing costs.

Methods based on the opportunity cost subtend the idea that human resources can be contended within an 
organization and, therefore, are assigned in the organizational centers that are willing to pay the highest price in terms of budget.

The replacement cost method consists in identifying the value of human capital defined as the total value of the hypothetical costs that a company would incur if it were to replace all employees.

The economic-income methods are characterized by an attempt to estimate the value of the share of revenue or services reasonably attributable to labour in future years.

An initial formulation provides that the value of human capital can be made equal to the sum discounted at a special discount rate of the expected annual income of the person for the period determined for the duration of the employment relationship.

Another model involves the possibility that the value of human capital is made equal to the product of two factors:

- The present value of expected salaries to be paid to workers for the following five years discounted at the company ROI;

- The efficiency index that measures the company ROI in relation to the industry average ROI, calculated as a weighted average of the last five years, giving more weight to more recent years.

The application of these methods, however, does not seem to be free from a number of application pitfalls, in fact, the variables are necessary for the operation of such models take into account the risk of a high level of subjectivity in the formulation of the assumptions underlying the estimation process.

It is necessary to point out that these methods may, however, be subject to the application of certain adjustments, including for example those relating to the mortality rate of workers. Thus, it has been duly pointed out that the probability of a decline over time in the value of the benefit must be appreciated by entering a specific risk component in estimating the discount rate in addition to the risk free rate and the risk premium.

One of the approaches used for the determination of the discount rate is the so-called build up approach:

$$
i=i_{1}+i_{2}+s c r+m d
$$

where:

$i$ is the discount rate;

$i_{1}$ is the risk-free rate, or the rate of return on substantially risk-free investments. This rate is calculated on the basis of the average yield (historical or future) of government bonds in the medium/long term, as it is believed that these securities represent a reliable proxy for the return on a risk-free asset;

$i_{2}$ is the premium risk;

scr is a higher rate due to the fact that investing in a specific activity, rather than in a securities portfolio, does not allow the elimination of the diversifiable risk (specific company risk). This higher rate is likely to cover specific risks of the business, associated with its financial structure, type of activity, places where it is exercised, the concentration of customers, and so on;

$m d$ is the increase in the rate applied to non-listed companies due to the fact that their actions are taking into account marketability risks that are higher than those of listed companies.

In estimating the discount rate, the latter two components are not computed because of the subjectivity inherent in their determination.

Thus, the rate of fair return on equity is equal to the sum of the risk-free rate and the risk premium. 
The estimate of the risk premium can take place through different methods, among these the capital asset pricing model (Sharpe, 1969) is of particular importance, according to this model the risk premium is determined by multiplying the beta-factor (which is a measure of operational and financial risk of the business) by the average premium of the market, given by the difference between the expected mean return of the stock market and the return on risk-free investments. In formula:

$$
i_{2}=\beta \times\left(R_{m}-i_{1}\right)
$$

where:

$i_{2}$ is the risk premium;

$\beta$ is the beta factor;

$R_{m}$ is the average market return;

$i_{1}$ is the risk free rate.

If the business is not listed, it is not possible to use the beta-factor, so the average beta of a sample of companies comparable with the business being valued will be used ${ }^{1}$.

The estimate of the rate cannot be separated from the compliance with the principle of consistency between flows and interest rates. In this sense, if levered cash flows (nominal or real) are to be discounted, they should be discounted at the rate of return on the equity capital (nominal or real), on the contrary, if unlevered cash flows (nominal or real) are to be discounted, they will be discounted at the weighted average cost of capital $i_{\text {wacc }}$ (nominal or real).

Empirical methods tend to give human capital a value equal to the product of the total annual cost and a variable coefficient within a range of values which in the most conceptually articulated formulation (Zanda \& Lacchini, 1994) varies between 0.33 and 2.5.

In formula:

$$
W_{c . u .}=\text { Mult } \times \mathrm{TPC}
$$

where:

Mult. represents the value of the multiplier that, in general, varies from 0.33 to 2.5 (Zanda \& Lacchini, 1994);

TPC is the total annual cost of labor inclusive of the accrued TFR.

The two authors identified as determinants of the multiplier the quality of research carried out in the company, the complexity of the financial problems of marketing and management style.

From an examination of the most commonly used valuation methods, it is possible to conclude that, although, as authoritatively observed, there is no optimal human capital valuation method, and therefore the choice of methodology must be carried out using a contingent approach in relation to the purpose of the estimate, the nature of the services and information available, it is possible to attempt to make some considerations regarding the identification of some corrections to be applied in the case in which it is necessary to proceed to the evaluation of contributions of work in cooperative enterprises or to perform the evaluation of their human organization.

\footnotetext{
${ }^{1}$ Even if the CAPM is the most widespread model in different empirical contests its value has been questioned by multifactorial models and in particular by the three factor model (Fama \& French, 1993). With regard to the empirical verification of the CAPM on the Italian stock market see the contribution of Bruni, Campisi, and Rossi (2006).
} 


\section{Valuation of Structural Capital}

The estimate of the economic value of capital structure involves the use of two alternative approaches: the cost-based approach and the value-based approach.

The first is based on the historical or reproduction cost depending on whether the economic value of structural capital derives, respectively, from the costs incurred for its creation or from the costs that a potential buyer would incur to develop technological solutions similar to those being estimated.

Historical cost includes expenditure incurred by the company for the activities of invention and application of technology, although it is not easy to apply this method, as there are many common costs incurred in the various research centers and the sum of the costs is not sufficient to give adequate information to potential investors.

The cost of reproduction represents all the costs which are necessary to realize a utility similar to the technology being estimated. The limitations related to the application of this method are related to the difficult identification of replacement knowledge in terms of utility to those available on the market and to the fact that the costs incurred for the creation of this technology cannot assure the same results.

The value-based approach assesses the future economic benefits, namely, the contribution that such technology can make to the profitability of the company, although it is difficult to define the flow of expected economic benefits. In fact, the future income differentials should arise from the difference between the economic benefits obtained prior to the use of the new technology and economic benefits that will result from the introduction of the same. Another problematic is the choice of the discount rate for future benefits and the definition of the finite life of technology. The latter ends at the moment it becomes obsolete or is imitated by competitors. Finite life is extended according to the protection that a patent provides for the new technology.

Technology valuation, carried out by discounting the flow of future benefits discounted at a rate that includes the pay for pure capital investment and risk, is a theoretical value of general, fair, and neutral exchange that satisfies the buyer and seller, who will find the sale or purchase of the property reasonable.

The exchange value of the technology is represented in the following formula:

$$
W_{x}=\sum_{s=1}^{k} C_{s}(1+i)^{-s}
$$

where:

$W_{x}$ is the value of the technology to be researched;

$C_{s}$ is the flow of benefits or competitive differentials brought about by technology to the firm in $k$ years;

$i$ is the discount rate of the flow of benefits that takes into account the risk and return for the pure capital investment.

In this regard, some propose the estimate of the economic value of basic research through a value-based approach according to insurance logic. In this direction, it is necessary to take into account the demand that perceives the need for new knowledge, the possibility of basic research to solve laboratory problems, in the course of the project, the benefits resulting from the sale of each product unit after the technology development.

The evaluation of basic research can be represented in the formula as follows:

$$
Y=\sum_{s=1}^{k} p_{i}\left(\Delta R_{i \% \neg m}\right)_{\mathrm{r} \% \neg \mathrm{t}-\mathrm{m}}
$$


where:

$Y=$ value of basic research project with k alternatives of employment;

$k=$ markets interested in the research in question;

$P_{i}=$ probability of exceeding the limits that do not allow the use of knowledge on market $i$;

$i=$ minimum net revenues, estimated with reference to market $i$;

$r \%=$ discount rate;

$m=$ estimate of the time required to operationalize the project on market $i$;

$t=$ period of time over which it is assumed the cash flows generated from market $i$ can be extended.

\section{The Valuation of Relational Capital}

Relational capital is identified in the trust relationships that are established between the company and the company stakeholders: this trust comes from the reputation which the company has acquired over time. The elements that distinguish relational capital are the company's reputation, trademark, image and so on.

The corporate trademark is an intangible item that can be evaluated independently with methods used for the evaluation of other intangible items.

From a qualitative point of view, valuation methodologies consider the ways in which the relationship between the company and its stakeholders is managed, from a quantitative point of view, evaluation methods take into account the value of meaningful relationships that the company establishes with the external environment.

Quantitative methods, in particular, are divided as follows:

- Methods based on empirical indicators;

- Methods based on costs;

- Financial methods;

- Economic-income methods.

The methods based on empirical indicators, complying with the principles of rationality and generality, consider the data and information found on the market: examples are the prices paid for trades that have actually taken place. The indicator corresponds to a percentage or to a multiplier applied to a budget quantity taken as a reference (e.g., revenues, net income, etc.).

The use of such methods is recommended where the application of other methods is not practicable. In fact, these are lacking in terms of rationality since they lack a theoretical basis and in general do not seem to prescind from the interests of the parties involved in the interaction.

Included among the empirical methods internationally recognized, there is the Interbrand method: the value of the trademark is determined by multiplying the flow of income that the same is able to generate for a given multiplication factor.

The multiplier expresses the potential future earnings of the trademark and can be estimated through a detailed analysis of some critical factors that give strength to the trademark: leadership, stability, target market, internationality, trend, flexibility, marketing support, and legal protection.

The methods based on cost estimate, in terms of costs incurred, the future economic benefits that can be generated by the asset being valued.

According to the cost configuration, it is possible to identify some estimation methods based on historical 
cost, increased value cost, replacement or reproduction cost, and cost of loss.

The historical cost is represented by all costs directly attributable to the creation of the trademark and corporate image, namely, all the factors that contribute to creating trust in the company: the cost of project design, development, registration, life maintenance, penetration and the propagation of the trademark on the market.

The historical cost does not consider the changes in the purchasing power of the currency and other economic phenomena which may represent the current value of a business asset.

Revalued historical cost, in fact, identifies the value of the brand by the re-expression, at current prices, of the costs incurred in the past to develop the resource, and not calculated among the assets on the balance sheet. The value obtained represents the cost that should be incurred today in order to have an intangible equivalent to the one purchased in the past.

The cost of reproduction is represented by the sum of the charges which, at the time of the assessment, would be necessary to incur in order to obtain a trademark with the same characteristics of the existing one and having the same reputation on the market.

There are two procedures that allow the determination of this value. The analytical procedure evaluates separately all the elements necessary for the estimate, such as, for example, unit prices, the time horizon over which to distribute the financial resources, the minimum rate of return required by the market for investments of the same risk level: The synthetic process is expressed in the following formula:

$$
\mathrm{Vr}=\mathrm{MT} * \mathrm{C}
$$

where:

$V r$ is the cost of "as new" replacement;

$M T$ is the capital ratio (or multiplier) in years. It indicates the duration of the process of rebuilding the brand and varies in direct proportion to its value;

$C$ is the cost configuration relative to the resources to be allocated to the formation of a brand equivalent to the estimated one.

The method based on the cost of loss has characteristics that are similar to the economic income methods: the cost of loss can be quantified by the difference between the income of the company's products using its own trademark and what it would achieve without it.

In the case of the trademark, the use of these methods involves the determination of its value according to the amount of past investments and not the future utility of the asset and the expected income.

The financial methods are based on discounted cash flows that the trademark can generate in future years.

The difficulties related to the precise identification of future cash flows that the trademark will be able to generate has induced some writers to prefer economic income methods, which identify the trademark value according to the amount that it provides to the overall profitability of the company. In particular, there is the discounting, for a given number of years, of the differential result obtained from the sale of a product with the trademark and the result obtained from the sale of a product without the trademark which is being valued.

The economic income method can be applied in view of the seller and buyer using the following formula:

where:

$$
W_{m}=R_{1} \cdot v+R_{2} \cdot v^{2}+\ldots+R_{n} \cdot v^{n}
$$

$W_{m}$ is the value of the trademark;

$R_{1}, R_{2} \ldots R_{3}$ is the expected differential income over time; 
$v, v^{2} \ldots v^{n}$ are the discount coefficients of the expected differential income;

$n$ is the number of years of expected useful life of the trademark, it expresses the life cycle of the trademark, its protectability and the predictable evolution of the market.

By substituting the above formula with the average future income " $\mathrm{R}$ ", there is the formula for the present value of $n$ years:

$$
W_{m}=R \cdot a_{n \neg i}
$$

Therefore, it seems necessary to note that in terms of the rationality of the evaluation method, it is preferable to use methods based on flows represented by the adjusted operating income of the value of the rebates.

In order to overcome the problems related to compliance with the requirement of independence or neutrality of the parties involved in the negotiation, it is possible to discount the differential incomes calculated on the basis of royalties.

The method of royalty determines the value of the trademark using the royalties: these represent data expressed by the market which take into account the characteristics of the trademark, the reference business sector and the characteristics of the market.

The value of the royalty ranges between $2 \%$ and $20 \%$ of the sales revenues in relation to the reference sector and is applied to future normal revenues achieved by the company for the sale of products covered by the trademarks being estimated, over a period between five and 20 years.

The formula for determining the economic value of the trademark is as follows:

$$
W_{M}=\sum_{t=1}^{n} \frac{F_{t} \cdot r}{(1+i)^{t}}
$$

where:

$W_{M}$ is the value of the trademark;

$r$ is the royalty;

$F_{t}$ is the normalized value of the expected revenues;

$n$ is the finite life of the intangible asset;

$i$ is the discount rate.

\section{The Synthetic Method for the Evaluation of Intellectual Capital (IC)}

The synthetic method considers the IC held by the company coinciding with goodwill.

The formula will be:

where:

$$
\text { Intellectual Capital }=\text { Goodwill }=\mathrm{W}-\mathrm{K}^{\prime}
$$

$W$ is the value of the economic capital of the holder of intellectual capital;

$K$ ' is the net worth of the firm, adjusted to reflect the restatement to fair value of the assets and liabilities that compose it.

The adjusted net equity is derived from the annual financial statements, or by the appropriately adjusted net accounting equity:

- It is necessary to identify the assets and liabilities of the company, excluding assets related to intellectual capital and which are registered in the financial statements;

- These elements are evaluated analytically according to their current values; 
- The adjusted net assets are determined.

For the estimation of $W$, to determine the economic value of goodwill, direct and indirect methodologies are used. These methods are based on quantities which are gathered from the market and are divided into:

- Direct methods in the strict sense: which are used to determine the value of economic capital based on the prices expressed by the market for the company in question (if listed), or on prices determined in extraordinary transactions for companies similar to the company being valued;

- Direct methods based on empirical multipliers: the value of the economic capital of the company is equal to the product between a market multiplier and a quantity of expression of the economic value of the share capital of the company;

- Direct methods in the strict sense can be further divided into two categories, depending on whether or not the company to be evaluated is listed on a stock exchange. In the first case, the economic capital of the company is calculated using the following algorithm:

$$
W=\sum_{i=1}^{n} P_{i} \times m_{i}
$$

where:

$W$ is the firm value;

$P_{i}$ is the market price of a type " $i$ " share (common or preferred share);

$m_{i}$ is the number of type " $i$ " shares.

In the second case, the company is not listed and the value of its economic capital is estimated as the simple or weighted arithmetic mean of the economic values assumed by a number of companies comparable to the one being valued. In formula:

$$
W=\sum_{i=1}^{n} W_{i}^{s} \times p_{i}
$$

where:

$W$ is the firm value;

$W_{i}^{\varsigma}$ is the economic value of the firms belonging to the sample, calculated on the basis of the "last prices" of transactions dealing with firms similar to the target firm;

$p_{i}$ are the "weights" given to each valuation.

The methods discussed up to this point also differ according to whether they are based on the criterion of the so-called equity approach to valuation or the entity approach to valuation.

In the case of direct methods on the equity-based approach to valuation, the estimate of economic capital is carried out in a direct way as follows:

$$
(W / k)_{T}=(P / k)_{s}
$$

where:

$(\mathrm{W} / \mathrm{k})_{T}$ is the multiplier of the company being estimated, given the relationship between the economic value of target firm $\left(\mathrm{W}_{T}\right)$ and a quantity $\left(\mathrm{K}_{T}\right)$ which expresses firm value (Net income, cash flow, revenues, etc.);

$(\mathrm{P} / \mathrm{k})_{s}$ is the market multiplier of a sample of companies similar, in quality and quantity, to the one being 
valued, which is constructed by comparing the market price of such firms $\left(\mathrm{P}_{s}\right)$ with the same quantity used for the calculation of the multiplier of the target firm $\left(\mathrm{k}_{\mathrm{s}}\right)$.

The value of economic capital is determined as follows:

$$
W=(P / k)_{s} \times k_{T}
$$

This formula implies the need to estimate:

(1) $k$ needs to determine the multipliers of the companies included in the sample of companies similar to the one being valuated;

(2) the value attributable to quantity $\mathrm{k}_{T}$.

There are many parameters $(k)$, for example, net income, operating income, cash flow, but the multipliers used very frequently in evaluation are:

- The price/earnings (P/E). The quantity $k$ coincides with the normal expected average profit;

- The price/cash flow (P/CF). The denominator is the levered or unlevered cash flow;

- The price/book value (P/BV). The denominator of the multiplier is represented by net assets.

The choice of parameters is performed according to the purpose of the evaluation and the information provided.

The ways in which the quantity $\mathrm{k}_{T}$ is estimated depend on the choices made for the definition of the multiplier: it can be represented by the net income (earnings), by cash flow, by net equity (book value) or by a quantity that can represent the value of the company being valued.

The practice of valuation suggests the use of medium-normal variables, purified of extraordinary components for each year in question and re-expressed in currency related to the valuation date using an appropriate inflation rate.

Direct methods based on the entity approach to valuation, however, estimate the value of the economic capital in an indirect manner by subtracting the market value of financial debts from the economic value of assets (firm value). The equality of reference is the following:

$$
(W+D / k)_{T}=(P+D / k)_{S}
$$

where the following is added to the known symbols:

$\mathrm{D}_{T}$ is the market value of the financial debts of the target company;

Ds is the market value of the debts of the sample of comparable firms.

The economic value of the activities of the firm (firm value: $W+D$ ) is obtained using the following formula:

$$
(W+D)_{T}=(P+D / k)_{s} \times k_{T}
$$

The economic value of equity is determined by deducting the total debt it incurs from the value of the economic activity of the valuated firm, in formula:

$$
W_{T}=(P+D / k)_{s} \times k_{T}-D_{T}
$$

The application of the formula involves the need:

(1) to define the value of the relationship between firm value (the sum of the market price of equity $P$, and the market value of debt $D$ ) and the quantity $k$ identified for the valuation of a sample of businesses similar the valuated company; 
(2) to determine the value to be assigned to variables $k_{T}$ and $D_{T}$.

The multipliers most commonly used in valuations for the definition of the parameter $k$ are:

- the firm value/earnings before interest and taxes (FV/EBIT), where $k$ is represented by Earnings Before Interest and Taxes (EBIT);

- The firm value/earnings before interest, taxes, depreciation and amortization (FV/EBITDA), where the parameter k coincides with the Earnings Before Interest, Taxes, Depreciation and Amortization (EBITDA).

To estimate the value attributable to the quantity $k_{T}$, valuation practice suggests the use of values of average expected normal EBIT and EBITDA $\mathrm{T}_{\mathrm{T}}$ referring to a period of three/ten years (historical or future).

The economic capital, in this case, is determined as follows, depending on whether the EBIT or EBITDA $A_{T}$ is used:

$$
\begin{array}{r}
W_{T}=(P+D / E B I T \quad)_{S} \times E_{\text {EBIT }}-D_{T} \\
W_{T}=(P+D / E B I T D A \quad)_{S} \times E_{T} B I T D A_{T}-D_{T}
\end{array}
$$

The application of the direct methods to the evaluation of goodwill undergoes obvious conceptual limits that are related, on the one hand to the lack of comparable listed companies.

A greater rationality is present in indirect methods that allow to identify configurations of income or financial flows consistent with the nature of the firm's performance.

The indirect methods of valuating economic capital are classified according to the variables on which they are based on: flow quantities, stock quantities or stock-flow quantities.

Indirect methods based on flow variables are divided into:

- Financial methods;

- Income methods;

- Methods based on distributable dividend flows.

Among the financial methods, there is the one based on the "total available cash flow". In formula:

$$
W=c i+f_{1} v^{1}+f_{2} v^{2}+\ldots \ldots \ldots . . .+f_{n} v^{n}+f_{n} v^{n}+f / i v^{n}
$$

where:

$W$ is the firm value;

$c i$ is the amount of cash at the time of valuation;

$f_{1}, f_{2}, \ldots f_{n}$ are the available monetary flows generated by the firm of the years considered;

$f$ is the average expected cash flow;

$v^{1}, v^{2}, \ldots v^{n}$ are the discounting factors based on cost of capital (i).

Income methods are based on the assumption that the economic value of a business is equal to the present value of expected income flows during the finite life of the business.

In formula:

$$
W=R_{1} v^{1}+R_{2} v^{2}+\ldots \ldots \ldots+R_{n-1} v^{n-1}+R_{n} v^{n}+R_{n}^{\prime} / i v^{n}
$$

where:

$W$ is the firm value;

$R_{1}, R_{2}, \ldots R_{n-1}$ are the income flows that the firm is capable of generating;

$R_{n}$ is the normalized expected income;

$v^{1}, v^{2}, \ldots v^{n-1}, v^{n}$ are the discounting factors in relation to a predetermined interest rate (i). 
The method based on the distributable dividend flows are based on the assumption that the economic value of the company is equal to the present value of all future dividends earned by those who invest risk capital in the company. In formula:

$$
W=D_{1} v^{1}+D_{2} v^{2}+\ldots \ldots \ldots+D_{n-1} v^{n-1}+D_{n} v^{n}+D_{n} / i v^{n}
$$

where:

$W$ is the firm value;

$D_{1}, D_{2}, \ldots D_{n-1}$ are the dividend flows that the company is able to distribute;

$D_{n}$ is the expected normal dividend;

$v^{1}, v^{2}, \ldots v^{n-1}, v^{n}$ are the discounting factors in relation to a predetermined interest rate (i).

Methods based on flow variables require the determination of expected cash flows and the identification of the discount rate.

The methods used for estimating future cash flows are generally:

(1) statistical methods;

(2) method based on planned results;

(3) innovation method.

Statistical methods are based on statistical techniques applicable to the historical data of the firm, relating to the last three to five years. They are used to evaluate companies which have been on the market for several years. The steps followed for the application of such methods are:

- Standardization of historical flows. Balance sheet values are turned into elements that express the company's ability to generate financial, income or dividend flows;

- The analysis of the stability conditions of historical flows, using simple statistical indicators such as variance and standard deviation or multivariate discriminate analysis;

- The choice of the statistical instrument to be used for the prediction of future cash flows, using the techniques of the simple or weighted arithmetic mean and regression analysis.

The method based on planned results refers to the financial results expected in the budgets and in long-term plans drawn up by the directors of the company target. It is used when the company has been on the market for a short time and therefore has few profits and history (Damodaran, 1999).

This method involves the normalization of the budget and a comparison of the historical basis of the expected results and the actual results.

The innovation method estimates flows based on plausible assumptions regarding future scenarios within which the company will operate. The steps for applying the method concern the identification of the scenarios, the evaluation of the reflections of these scenarios on the main balance sheet figures, the estimated future cash flows based on the assumptions made.

An additional technique, compared with the previous ones, is the phase method by which the determination of future cash flows derives from breaking down the time horizon of the estimate into more than one period. The first three years are related to the budget values of the firm, up until five years it is possible to identify trends through regressive techniques, for the following years the average values are estimated. For the application of the methods based on income flows it is appropriate to normalize income according to the effects of mutual management and any accessory management.

With regard to the estimate of the discount rate, refer to what was previously explained. 


\section{A Conclusive Proposal}

A final methodological proposal for the identification of a course for the evaluation of human capital cannot be separated from the analysis of the evolutionary dynamics of knowledge in the company.

The process of formation, codification, and transfer of knowledge is closely connected with the life of the company and its evolutionary cycle.

Therefore, it seems appropriate to assume, using intersection logic, a positive correlation between the value of human capital and the presence of investment including investments in capital structure.

It is possible to consider that the creation of value and the development of human capital are closely connected with the presence in the company of components such as structural and relational capital.

It does not seem possible to envisage the economic value of human capital without appreciating the effects that result from the presence of other components of intellectual capital.

In this sense, it seems useful to propose an empirical methodology that provides a modified algorithm compared with empirical methods involving the application of multipliers to the total annual cost of labour.

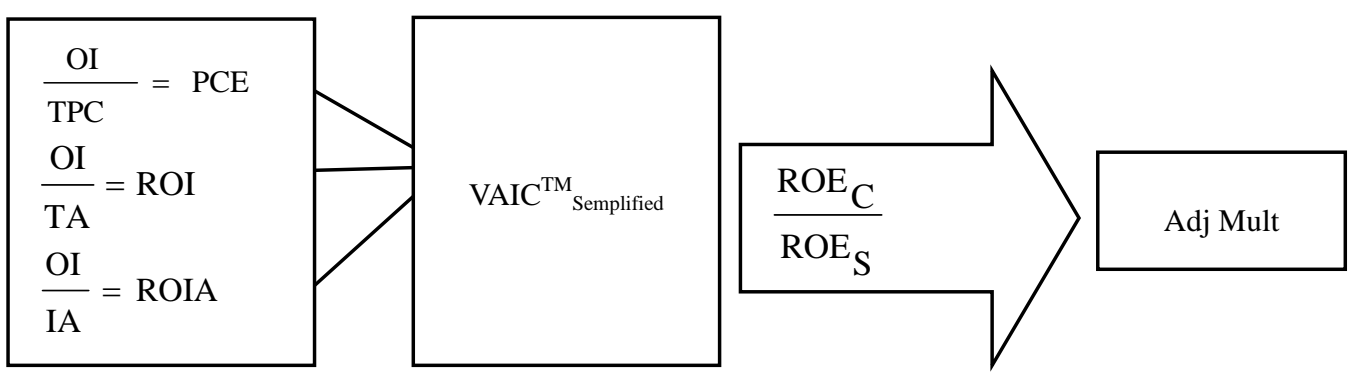

Figure 1. Theoretical framework.

The aim of this study is to identify a set of mutually related indicators which identify, in a verifiable manner, the determinants of these positive correlations based on the data that is present in the company's external informative report. On the basis of this requirement, it is possible to propose a simplified methodology assuming, on the basis of a series of empirical evidence, the positive correlation between VAICTM and ROE. The algorithm that follows is a simplification of an empirical method that provides for the estimate of the economic value of human capital:

$$
W_{c . u .}=\text { Mult } \times \mathrm{TPC}
$$

Where the symbols meaning that are already known.

The identification of an indicator used to develop a multiplier which correlates the EVCI with the ROE can be carried out as follows:

$$
\text { Adjusted Multiplier }=\text { VAIC }^{\mathrm{TM}}{ }_{\text {simplified }} * \frac{\mathrm{ROE}_{\mathrm{C}}}{\mathrm{ROE}_{\mathrm{S}}}
$$

In this algorithm VAIC can be identified according to the following simplification:

$$
\text { VAIC }^{\text {TM }}{ }_{\text {simplified }}=\frac{\mathrm{OI}}{\mathrm{PCE}}+\frac{\mathrm{OI}}{\mathrm{TA}}+\frac{\mathrm{OI}}{\mathrm{IA}}
$$

This formulation allows to obtain an easily verifiable proxy on the basis of the assumptions that follow:

(1) $\frac{\mathrm{OI}}{\mathrm{TPC}}$ is the Personal Cost Efficiency Ratio (PCE) and it provides information on the effectiveness of the cost of labor and thus indirectly the productivity of human capital; 
(2) $\frac{\text { OI }}{\mathrm{IA}}$ is the Rate of Return on Intangible Asset (ROIA) and is a proxy of the operating profitability on investments in structural capital;

(3) $\frac{\mathrm{OI}}{\mathrm{TA}}$ is the Rate of Return on Investment (ROI) and represents an indicator of efficiency of investment.

In this sense, the proposed simplification of the $\mathrm{VAIC}^{\mathrm{TM}}$ allows to define a measure of the profitability of human capital, of investments in intangible assets and of the total investments.

This indicator multiplied by the ratio between the company ROE and that of the business sector allows the identification of a multiplier that takes into account the risk of the net performance of the company compared with the reference sector.

In conclusion, it can be affirmed that the proposed simplification allows to identify multipliers with an appropriate level of rationality even in companies that do not adopt models and instruments of voluntary informative reports on the subject of intellectual capital, using readily available and comparable data which is present in the company's external informative report.

On the rationality level, it can be affirmed that this proposal should be able to allow the achievement of an adequate level of rationality in that it takes into account the development dynamics of human capital on the basis of the development, codification and transfer of knowledge that becomes structural capital and on the basis of the efficiency of operations that are placed in relation to the dynamics of the net profitability of the company compared to the sector with a view to creating value for shareholders.

This framework is the first step of a larger research project which will conclude with an empirical investigation of a sample of Italian listed companies with a high cognitive intensity.

\section{References}

Aboody, D., \& Lev, B. (2000). Information asymmetry, R\&D, and insider gains. Journal of Finance, 55(6), 2747-2766.

Bornemann, M., Knapp, A., Schneider, U., \& Sixl, K. I. (1999). Holistic measurement of intellectual capital, international symposium: Measuring and reporting intellectual capital: Experiences, issues and prospects. Retrieved from http://www.oecd.org/dataoecd/16/20/1947871.Pdf

Bruni, F., Campisi, D., \& Rossi, F. (2006). Capital asset pricing model e three-factor model. Un'analisi empirica sul mercato azionario italiano. In C. Leporelli (Ed.), XVII Riunione Scientifica Nazionale AiIG. Retrieved from http://www.ingegneriagestionale.uniroma1.it/aiig2006/atti\%20convegno/pdf/Bruni_Campisi_Rossi\%20.pdf

Celenza, D., Nappo, F., \& Lombardi, R. (2010). Intellectual capital reporting: An innovative model to represent company’s invisible asset. Proceedings of the 7th International Conference on Intellectual Capital, Knowledge Management \& Organisational Learning (pp. 555-566). The Hong Kong Polytechnic University, Hong Kong, China.

Chen, M. C., Cheng, S. J., \& Hwang, Y. (2005). An empirical investigation of the relationship between intellectual capital and firms' market value and financial performance. Journal of Intellectual Capital, 6(2), 159-176.

Cricelli, L., \& Grimaldi, M. (2009). Intangible asset contribution to company performance: Hyerarchical assessment index. VINE, 39(1), 40-54.

Damodaran, A. (1999). The dark side of valuation: Firms with no earnings, no history and no comparables. Retrieved from http://papers.ssrn.com/sol3/papers.cfm?abstract_id=1297075

Drucker, P. F. (2003). Il management della società prossima ventura. Milan: Etas.

Edvinsson, L., \& Malone, M. S. (1997). Intellectual capital: Realizing your company's true value by finding its hidden brainpower. New York, N.Y.: Harper Business.

Fama, E. F., \& French, K. R. (1992). The cross-section of expected stock returns. Journal of Finance, 47(2), 427-465. 
Firer, S., \& Williams, S. M. (2003). Intellectual capital and traditional measures of corporate performance. Journal of Intellectual Capital, 4(3), 348-360.

Ghosh, S., \& Mondal, A. (2009). Indian software and pharmaceutical sector IC and financial performance. Journal of Intellectual Capital, 10(3), 369-388.

Grazzini, E. (2008). L'economia della conoscenza oltre il capitalismo: Crisi dei ceti medi e rivoluzione lunga. Turin: Codice Edizioni.

Grossman, S., \& Hart, O. (1986). The costs and benefits of ownership: A theory of vertical and lateral integration. Journal of Political Economy, 94(4), 691-719.

Hart, O. (1995). Firms, contracts and financial structures. London: Oxford University Press.

Hart, O., \& Moore, J. (1990). Property right and nature of the firm. Journal of Political Economy, 98(6), 1119-1158.

Hart, O., \& Moore, J. (1994). A theory of debt based on the inalienability of human capital. The Quarterly Journal of Economics, 109(4), 841-879.

Kamath, G. B. (2008). Intellectual capital and corporate performance in Indian pharmaceutical industry. Journal of Intellectual Capital, 9(4), 684-784.

Lev, B. (2001). Intangibles: Management, and reporting. Washington, D. C.: Brookings institution press.

Lev, B., \& Radhakrishnan, S. (2003). The measurement of firm-specific organization capital. NBER Working Paper, No. 9581. Retrieved from http://www.nber.org/papers/w9581

Lev, B., \& Zarowin, P. (1999). The boundaries of financial reporting and how to extend them. Journal of Accounting Research, 37(2), 353-385.

Moore, J. (1992). The firm as a collection assets. European Economic Review, 36(2-3), 493-507.

Petty, P., \& Guthrie, J. (2000). Intellectual capital literature review: Measurement, reporting and management. Journal of Intellectual Capital, 1(2), 155-175.

Prandstraller, G. P. (2009). L'imprenditore quaternario. Milan: Franco Angeli.

Pulic, A. (2000). MVA and VAIC ${ }^{\mathrm{TM}}$ analysis on randomly selected companies from FTSE 250. Retrieved from http://www.vaic-on.net

Rifkin, J. (2001). L'era dell'accesso: La rivoluzione della new economy. Milan: Mondadori.

Rifkin, J. (2010). La civiltà dell'empatia: La corsa verso la coscienza globale. Milan: Mondadori.

Sharpe, W. (1964). Capital asset prices: A theory of market equilibrium under conditions of risk. Journal of Finance, 19(3), 425-442.

Stewart, T. A. (1997). Intellectual capital: The wealth of new organizations. London: Nicholas Brealey Publishing.

Sveiby, K. E. (2001). Methods for measuring intangible assets. Retrieved from http://www.sveiby.com/TheLibrary/IntangibleAssets/tabid/81/Default.aspx

Trequattrini, R. (2008). Conoscenza ed economia aziendale. Naples: ESI.

Venugopal, D., \& Subha, M. V. (2012). Intellectual capital and value creation efficiency-An empirical investigation into the intellectual capital and financial performance of Indian software industry. European Journal of Social Sciences, 33(1), 119-132.

Zanda, G. (2009). Il governo della grande impresa nella società della conoscenza. Turin: Giappichelli.

Zanda, G., \& Lacchini, M. (1994). La valutazione delle aziende. Turin: Giappichelli.

Zanda, G., Lacchini, M., \& Oricchio, G. (1993). La valutazione del capitale umano dell’impresa. Turin: Giappichelli. 